\title{
Notas sôbre a história dos impostos em Direito Romano*.
}

\author{
Alexandre Augusto de Castro Corrêa \\ Catedrático de Direito Romano na Faculdade \\ de Direito da Universidade de São Paulo.
}

Umas das características essenciais dos Estados desenvolvidos é o incremento dos servicos públicos e da conseqüente necessidade de fundos para atendê-los, de modo ao cidadão ser chamado a contribuir para a formação do erário. Em Roma, o peso da carga tributária dependeu do desenvolvimento da civilização, e com a formação do Império, foi aumentando sempre até, na última fase do domínio romano, ser esmagador, constituindo mesmo junto com as guerras constantes contra os bárbaros uma das causas da ruina do Império. Estreitamente unida a ela andaram a constituição de monopólios, os latifúndios ${ }^{1}$ e a economia dirigida do período romano bizantino.

*. Tendo-nos, infelizmente, até agora, faltado o tempo necessário para a realização de trabalho original sôbre assunto tão afastado de nosso ensino d'instituições do direito privado romano oferecemos aos leitores simples materiais de leitura, na esperança de sermos úteis aos especialistas, porventura interessados em investigações históricas.

$\mathrm{Na}$ exposição das noções seguimos sobretudo a LETOURNEAU, autor do antigo mas excelente e assaz conhecido L'Évolution Politique dans les diverses races humaines e ao professor GIUSEPPE LuzZatTo, egrégio romanista cotemporâneo da Universidade de Bolonha. Publicou êste mestre excelente estudo sôbre os Impostos em Direito Romano, aparecido no tomo oitavo do Novissimo Digesto Italiano. Salvo, pois, um ou outro comentário, no corpo do trabalho, são de nossa lavra apenas a roupagem portuguêsa de idéias alheias e a... bibliografia selecionada abaixo.

1. É conhecida a frase de Plinio: "Latifundia perdiderunt Italiam" 
Nos primórdios, entretanto, na civilização romana a tributação é escassa e eventual. As funções administrativas, atribuídas ao Estado, eram a princípio reduzidas, predominando as "gentes" a bem dizer autárquicas. É a razão talvês pela qual Cícero ${ }^{2}$ define o imposto ou "vectigal" como: "Quasi victoriae proemium ac poena belli": o imposto é para os romanos antes de mais nada sinal durável de conquista, atestando a supremacia e a soberania do Estado romano sôbre povos estrangeiros. Porisso, até à época de Diocleciano, o solo itálico era quase isento de impostos, cobrados pelo contrário aos possuidores de terras provinciais, cujo domínio, em conseqüência da conquista, passara ao Estado romano, o qual por sua vêz concedia aos vencidos o uso e gôzo das terras, mediante pagamento de tributo ou "vectigal" ("jus in agro vectigali"), originando, aliás, uma espécie de propriedade, distinta do originário "dominium ex jure quiritum", a propriedade provincial. Reformando o Estado, estendeu Diocleciano a tributação aos prédios itálicos, extinguindo o privilégio do qual gosavam. Poderíamos daí concluir tivesse o Estado romano assumido o domínio ("dominium") das terras, até então pertencentes aos "quirites", rebaixados à categoria de possuidores, sujeitos, inclusive, ao confisco, em caso de comisso? É possível, embora não possamos aqui entrar nos pormenores do assunto.

Nos mais antigos tempos de Roma os esporádicos serviços prestados pelo Estado aos cidadãos chamavam-se "liturgias" ou "munera". O primeiro nome é grego: "leiturgia", significa, em grego, serviço público. A palavra se decompõe em "leitos, leita, leiton", "público", e "érgon, érgou", "obra". Já "munus", "muneris" é palavra de ori-

2. "Verrinas", II, III, 6. Vêr também GaIo 4, 16: "As partes usavam a varinha ("festuca") em lugar da lança ("hasta") para simbolizar o justo domínio; pois acreditavam-se proprietárias sobretudo do arrebatado aos inimigos; daí o colocar-se uma lança diante dos tribunais dos "centúmviros". 
gem latina, donde vem, aliás, "municipium" e "municeps", municipis", "municipe" Significa encargo público, abrangendo os impostos diretos, as funções de tutor, curador, o serviço militar, etc. Ora, no período régio os "munera" eram na verdade servicos prestados diretamente pelo particular ao Estado romano e proporcionais à sua fortuna, de acôrdo, já na República, com a repartição dos cidadãos em centúrias e tribus e com o recenseamento cuja finalidade originária, segundo o romanista Luzzatro $^{3}$ era militar (organização do exército) e religiosa (cerimônia da "lustratio"). A divisão, pois, efetuada por Servio Tulio, dos cidadãos em cinco classes, de acôrdo com sua riquesa, não teria sido inspirada por nenhum intuito fiscal. O "munus" é, portanto, capitação pessocl. Quais as suas caracteristjcas exatas, na realeza? Mommsen tenta defini-las encarando-o como empréstimo compulsório, semelhante à "eisfora" grega. O reembolso se faria aos cidadãos depois de alguma vitória. Tal hipótese, observa Luzzatto, embora engenhosa, não encontra apoio na tradição histórica de Roma.

\section{Impostos diretos.}

Graças a adaptações a divisão em classes de Servio Tulıo veio, já na República, a originar o "tributum ex censu", segundo o qual cada um era taxado de acôrdo com sua riquesa, ficando isentos só os "proletárii" cujo único bem era a "proles" Êsse imposto, recaindo também sôbre a terra, era dum milésimo do valor do capital e dêle se isentavam só os sacerdotes e os militares em serviço ativo. Sua cobrança era realizada pelos tribunos do tesouro, de acôrdo com declaração feita pelo cidadão, sob forma de "professio censualis" (D, 50, 15, 4) e constando das "tabulae censoriae" do censor, cujo poder discricionário

3. LuZzatTo, "Preliminares históricas dos Impostos em Direito Romano, in Novissimo Digesto Italiano, v. "Imposta", vol. VIII, pp. 304-305. 
era tão grande, nesta matéria, a ponto de se converter em verdadeiro monopólio da administração financeira. Depois da terceira guerra macedônica (172-168 a.C.) o imposto, por mais dum século (até 43 a.C), deixou de ser cobrado aos cidadãos romanos onerando, pelo contrário, só os provinciais. A êstes se aplicou a distinção entre "tributum soli" gravando a terra ("jus in agro vectigal") e, "tributum capitis" ou capitação, revelando a sujeição política. Fundamento da cobrança do primeiro era a idéia segundo a qual, em conseqüência da conquista, o domínio passava ao Estado romano ficando os provinciais só com a posse das terras.

A partir de Augusro (27 a.C. - 14 d.C.) o imposto foi assumindo cada vez mais caráter monárquico acabando por desaparecerem (III. ${ }^{\circ}$ século) as províncias chamadas senatoriais, absorvidas nas imperiais administradas por prefeito do imperador 4 . Augusto mandou fazer cadastro visando conhecer a exata extensão das propriedades tributáveis, trabalho êste exigindo trinta anos para sua conclusão. Nos fins do Império chamavam-se "censuales" os fiscais das listas censitárias e respectivas declarações; os "censitarii" avaliavam as quantias tributáveis $(\mathrm{C}, 11,58)$ e fiscalizavam os registros municipais.

\section{Impostos indiretos.}

A partir dos fins da República o tesouro adquire rendas crescentes mediante numerosos impostos indiretos, indicados, de modo geral, pelo termo "vectigal" e impròpriamente por "tributum" durante o principado. Chama-se, em sentido próprio, vectigal a contraprestação paga pelos concessionários do "ager publicus" (jus in agro vectigali") ou de arrendamentos públicos. Integrava o "ager publicus" a terça parte das terras conquistadas e arrendadas ("vecti-

4. Sôbre ambas as espécies de províncias, vêr Gaio II, 15 e 21. 
gal") pelo censor aos particulares por um lustro. O mesmo termo "vectigal" designa, ainda, as somas pagas pelos provinciais em conseqüência da reforma, por Calo Graco, das "decimae" 5 da Ásia e da Sicília. "Ager scripturarius" era o terreno público arrendado para pastagem mediante pagamento aos publicanos de "scriptura" ou aluguél. Dentre os "vectigalia" sobressaía o "portorium", imposto sôbre as mercadorias importadas ou exportadas pelo Império.

Até Tibério e Marco Aurélio prevalece o antigo sistema de arrendamento da cobrança dêsses impostos primeiro as grandes "societates publicanorum", formando pessoa jurídica de direito privado, como, nos tempos modernos, durante o Antigo Regime, acontecia freqüentemente na Europa. Depois, a exação é assumida diretamento pelo Estado, na pessoa do procurador imperial. As taxas aduaneiras de importação iam "ad valorem" de $2,5 \%$ a $16,5 \%$ sobretudo em se tratando de objetos de luxo; as de exportação eram de apenas 2,5\%. Como Atenas, observa Letourneau, a quem, com Luzzatro, vimos seguindo, Roma não praticou o câmbio livre. A "centesima rerum venalium" (1\%), instituída durante as guerras civis e cobrada por "coactores" especiais, adjuntos aos publicanos, atingia tôdas as vendas. Foi por Tibério reduzida à metade e abolida por Calígula. A "vicesima hereditatum et manumissionum" (5\%) era cobrada sôbre as heranças de pessoas ricas as quais tivessem direito só por testamento e não por lei ("heredes extranei"). Estabelecido o imposto desde 5 d.C., os imperadores procuram estendê-lo a tôdas as transmissões, sendo esta mesma a razão pela qual, a fim de generalizá-lo, Caracala, em 212, concedeu a cidadania romana a todos os habitantes do Império. A mesma taxa, por fôrça das leis "Julia et Papia-Poppaea" era cobrada aos herdeiros celibatários. "Ostiarum", taxa sôbre as portas duma casa, era

5. "Décima" é termo usado para significar tributo civico recaindo sôbre a décima parte de qualquer renda tributável; por extensão indica o montante de qualquer contribuição direta. 
às vêzes cobrada nas províncias; o "aurum coronarium", de oferta voluntária passa, no Baixo Império, a tributo regular.

\section{“Societates Publicanorum".}

Durante tôda a República e o Principado, os romanos, diz LuzzatTo, cobraram os impostos mediante o sistema de concessão às "societates publicanorum" as quais, desde a época dos Gracos, pagavam, antecipadamente, ao Estado a soma estipulada por êste como devendo corresponder ao exercício vencido; depois ficavam livres de cobrar quanto quisessem aos provinciais. Para tanto, os publicanos aliavam-se aos procônsules, praticando abusos, tornando-os odiosos às populações e fazendo do nome "publicano" símbolo de avidez e falta d' escrúpulos. Os contratos de arrendamento dos impostos, feitos com o Estado, apresentam a peculiaridade seguinte: êles se realizavam entre o Estado, dum lado e a pessoa física do "manceps" do outro, representante da "societas publicanorum" a qual não intervinha diretamente. A responsabilidade, além disso, sôbre a pessôa e os bens, em conseqüência das dívidas resultantes do contrato, era assumida por outra pessoa física, o "praes", Discute-se, porisso, a respeito da verdadeira natureza juridica das "societates publicanorum" bem como sôbre a natureza das relações entre seus membros e o "manceps" ${ }_{6}$

As despesas públicas, durante o Império, tenderam a aumentar sempre por causa da necessidade de manter exército permanente, do número cada vez maior de funcionários e dos gastos com uma côrte suntuosa. A arrecadação d'impostos foi-se, porisso, tornando sempre mais urgente e contribuindo para a eliminação da autonomia administrativa das províncias, consumada pelos Antoninos.

O despotismo do príncipe acabou tornando-se absoluto: "Quod principi placuit, legis habet vigorem". Dioclecrano

6. Luzzatto, no artigo citado in Novissimo Digesto Italiano. 
afinal, extinguiu os últimos vestígios das instituições republicanas, criando-se, daí por diante, circunscrições artificiais, só para a cobrança de impostos, desfrutados por um exército de funcionários constituindo a nobreza administrativa dos "ilustres", "spectabiles", "clarissimi", "perfectissimi", "egregii"; "nobilissimi" eram os principes da causa imperial. ${ }^{7}$

O fiscalismo excessivo do Baixo Império foi, como se sabe, uma das causas da decadência e da queda do Império Romano, tão magistralmente descritas por GiBBon.

\section{Bibliografia}

DUverger, MaUrice, Finances Publiques, 1 vol. PUF, 1968,; Théorie générale de l'impôt, pág. 367 e ss.; resumo do mesmo autor in "Que sais-je?" n. ${ }^{\circ} 415$.

Outros números de "Que sais-je?" sôbre impostos: 339 ( Le sel), 651 Histoire de l'impôt, 846 Les douanes," 1109, Finances et financiers de l'ancien Régime", 1217 "La monnaie et ses mécanismes", 1222 "La politique des revenus", 726 "Le bilan dans les entreprises."

Mommsen, Vol. $10^{\circ}$ De l'organisation financière chez les Romains Paris, 1888.

SERRIGNy, Droit public et administratif romain. Tome II, Livre II, Titre I, Chap. VU. Des choses fiscales, pp. 1-222. Livre III, Conditions économiques et sociales des personnes. Des diverses professions classées. Du colonat. pp. 349 e ss.

Jura, XIX, 1968 - Parte seconda, XV, Diritto Pubblico, p. 301 e ss. LANDogna, Storia d'Italia, 1 vol. 1957, pp. 11-14.

Ellul, JACQUes., Histoire des Institutions, t. 1.', PUF, 1955. "Impôts", "Institutions financières d'Athènes" p. 130; pp. 135, 142/3; 192 e ss., 296, 332, 340, 431, 472/3, 508, 562, 613, 694, 728.

IMBERT, Histoire des Institutions et des faits sociaux I. "Des origines au Xe. siècle" 1 vol. PUF, 1957; II. Xe., XIXe. siècles, 1956.

7 Letourneau, Ch. - L'évolution Politique dans les diverses races humaines, 1 vol. Paris, 1890. Vêr, especialmente, as páginas 481-484. 
RosTovzeFr, M. The social and economic history of the Roman Empire, 2 vols. Oxford, 1957.

Vêr, Tax collectors, Taxation, Taxes, Taxes on cauctions, T'axes for the exercise of a trade.

SANDYs, $A$ companion to latin studies, Cambridge, 1938, v. Finance (pp. $342 / 352)$.

Chastagnol, La préfecture urbaine à Rome sous le Bas-Empire, p. 335 e ss.

Novissimo Digesto Italiano "Accensi", I,1 pp. 121-122. Imposta (Diritto greco, Diritto Romano, Diritto Intermedio"). VIII, pp. 300-310.

Gaudemet, JeAn Institutions de l'Antiquité, Paris, 1967. - Vêr a bibliografia sôbre Société-f́conomie-Civilisation (p. VIII).

Impôts. Égypte lagide, pp. 242/3; "Égypte pharaonique" 69, 74, 76; "Grèce." 173; 213. "Monarchie d'Alexandre" 221,; Monarchie hébraique" 105, 109; "Monarchie héllénistique" 228; "Rome" 494, n. $3 ; 503,511$ et n. $7 ; 517 ; 530 / 531 ; 680$ n. $6 ; 681 ; 700,704,705$, 708,713 n. 8.

Histoire Générale des Civilisations, tome II.

Rome et son Empire - par Aymard e Auboyer, Paris, PUF, 1 vo.1 1959. La Civilisation carthaginaise - La vie économique et la richesse, p-41-44,; Les gaulois pp. 60 e ss.

Rome républicaine, Évolution économique et sociale pp. 136 e ss.

Les sociétés de publicains, p. 149.

La crise: "latifundia" et "ager publicus" (p. 161 e ss.).

Les finances: inégalité fiscale entre l'Italie et les provinces p. 295.

Vie économique et sociale, p. 304 e ss.

La première inflation de l'histoire, p. 467.

Les Finances - pp. 507-512, L'administration locale et régionale p.

512 e ss.

Les nouveautés économiques et sociales (p. 530/536).

La société laique (p. 537 e ss.)

Puissance économique de l'Eglise, p. 552.

La mort et le legs de Rome antique, p. 594 e ss.

Les causes de l'éffondrement 596; Le legs de Rome 599-600.

Grimal, Pierre, La Civilisation romaine, Arthaud, 1960.

Ver no Dictionnaire do mesmo livro, o verbete "Impôts".

GaGÉ, JEAN, Les classes sociales dans l'empire romain, Paris, Payot, 1 vol. 1964.

LetouRneaU, L'évolution politique dans les diverses races humaines, 1 vol. Paris, 1890. Cap. XVIII. L'évolution de l'impôt (pp. 462/489).

MeIRA, Sílvio, Direito Tributario Romano, in "Romanitas", Revista de Cultura Romana; vol. 10, tomo II, pp. 279-330, Rio 1970. 